\title{
Distributed Generation of one kind of Networking Mode and the Power Relations Analysis between Large AC Power Grid and Distributed Generation Grid
}

\author{
Jianye Liu, ${ }^{1, a}$, Xiaolong Sun ${ }^{2, b}$, Zhanwen Fu ${ }^{3, c}$ \\ ${ }^{1}$ School of Electrical Engineering, Hebei University of Technology, Shijiazhuang,050081,China \\ ${ }^{2}$ School of Electrical Engineering, Hebei University of Technology, Shijiazhuang,050081,China \\ ${ }^{3}$ School of Electrical Engineering, Hebei University of Technology, Shijiazhuang,050081,China \\ aemail:liujianye9988@sina.com, bemail:676639913@qq.com, cemail:fuzhanwen@163.com
}

Keywords: New Energy; Distributed Generation(DG) Systems;Connected to the Grid; AC Micro-grid; Power Angle; Power Factor

\begin{abstract}
For the problems of distributed generation new energy connecting to the grid, a networking mode with dual PWM DC / AC power supply interface is proposed, This mode can achieve a large grid and micro-grid communication partitions, The operation and management of distributed power generation system is more flexibility, Control strategy is more richer,and the AC micro-grid electricity users is more secure. Analysised from the DC bus into the large micro-mesh grid side equivalent model, three control modes is presented to Grid Interface DC / AC : Charging, discharging mode and synchronous condenser mode, And at the three modes, the power relations is analysised between large grid and DG grid .
\end{abstract}

\section{Introduction}

With the acceleration development of urbanization and high-rise buildings into construction, near the load of center development distributed new energy generation system, and embedded power lines into the AC transmission network, it has increasingly become a new way of new energy development and utilization[1].But because of a variety of distributed generation primary energy, capacity is too small 、apparently intermittence and uncertainty of power generation, easily cause to harmonic pollution, voltage interruption and waveform flicker problem and so on. Combined with the power network in active and inactive power flow control is insufficient, and the load level of transmission line lack of control means, so including wind power and photo-voltaic power generation the main bottleneck of the development of new energy is grid-connected [ 2 ].

\section{A network model of distributed generation}

In recent years, flexible DC transmission technology has become a worldwide research hot-spot, Because of the flexible DC transmission can be adapted to the off-grid island transmission without grid supporting commutation , and also can be used to active power transmission when grid-connected running, the reactive power of busbar dynamic compensation, busbar voltage amplitude stability, etc. Therefore, flexible DC transmission technology is effective means to assure the safety of regional power supply 、 breakthrough of new energy grid bottlenecks、 improve power quality ,etc , is a key technology of the intelligent grid [3].

DC micro-grid concept is currently no uniform definition, but micro-grid into the public grid and network technology requirements can be summarized the following points [4] : (1) The micro-grid should be a modular control power, must have a good network control and management system; (2) Micro-grid should be an autonomous operation, provide stable power to the load and voltage support; (3) Isolated operation is the most important micro-grid capacity.

Compared with the single PWM DC/AC power interface grid has the following advantages: 
Does not support the delivery of electricity to the grid, seamless connection with power grid; (2) Transmit to AC micro-grid ,independent power generation as the main ,public power grid transmission as supplement; (3) Distributed generation systems and its load with equivalent capacitive load characteristics, for large power grid with reactive compensation; (4) Capable of island operation and has strong low voltage penetration ability.

\section{Grid mode of distributed generation DC micro-grid public power side and control model of the flexible DC transmission}

Distributed generation has the diversity of primary energy, power generation unit capacity is small, power generation process characteristics of the intermittent or discontinuous, so the DC micro-grid distributed generation in the steady state model in general should be determined by the energy storage device, DC micro-grid transmission lines, power electronics power transducer, the exchange of transmission lines[5],as shown in figure 1.

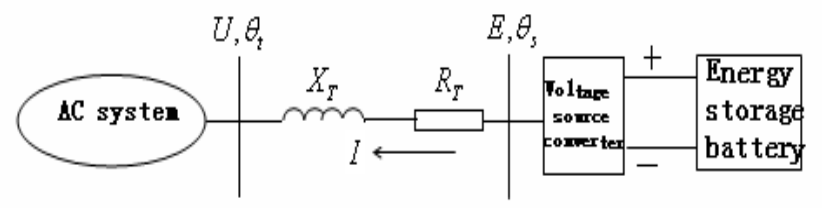

Fig.1 Grid connected model of photo-voltaic power generation

Grid-connected power interface control with distributed generation system has three work modes, namely the discharging mode, charging mode and the synchronous condenser model.

\subsection{Charging mode and discharging mode}

Under the charging mode, the voltage equation of the grid-connected side is:

$\dot{U}=\dot{E}+\dot{I} R_{T}+\dot{j} \dot{I} X_{T}$

Under the charging mode, the voltage equation of the grid-connected side is:

$$
\dot{E}=\dot{U}+\dot{I} R_{T}+\dot{j} \dot{I} X_{T}
$$

Ignore AC reactor resistance, figures2 (a) and 2 (b ) are shown the formula (1), (2) the power factor angle time phasor diagram within the range of $-90^{\circ}\left\langle\varphi\left\langle+90^{\circ}\right.\right.$.In figure $\theta$ is phase difference which between the $\dot{U}$ and $\dot{\mathrm{E}}$, also known as the power angle. $\varphi$ is phase angle which between current i and voltage $\dot{U}$,namely power factor angle.

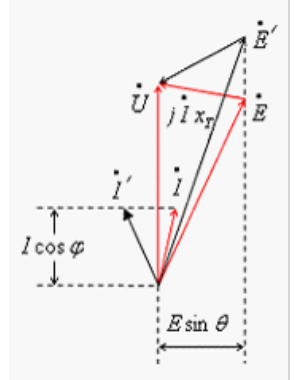

2(a) Energy storage battery charge

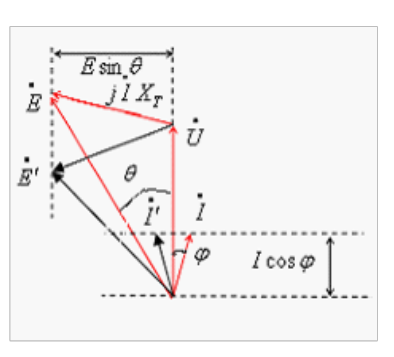

2(b)Energy storage battery discharge

Fig.2. The constant power charge/discharge vector diagram of energy storage battery

As can be seen from the phase diagram,if control voltage source inverter let the AC side voltage $\dot{\mathrm{E}}$ phase lags behind grid voltage $\dot{U}$, is the energy storage battery charging ${ }_{\mathrm{C}}$ ontrol mode, control voltage source inverter let the AC side voltage $\dot{\mathrm{E}}$ phase ahead of grid voltage $\dot{U}$, is the energy storage battery charging control mode.

\subsection{The synchronous condenser model[6]}

Energy storage battery charging and discharging work condition, if adjustment of power angle $\theta=0^{\circ}$, will make the power factor angle $\varphi$ of distributed generation system transmission line reaches 900 . Such as vector figure 3 (a), (b), 

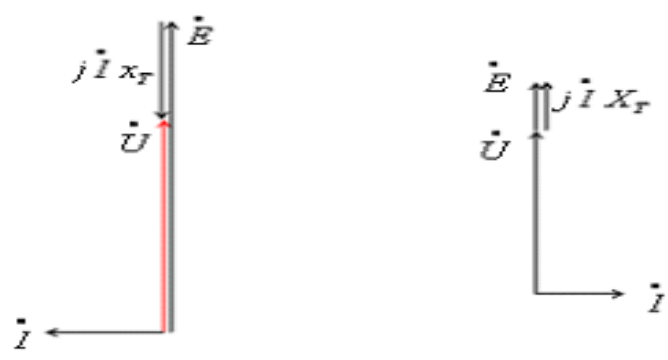

3(a)Inductive reactive power compensation3(b)Inductive reactive powercom pensation

Figure .3.PV systems synchronous condenser control mode vector graphics

The distributed generation system is now running at near zero power input and output and zero power factor condition.Especially the energy storage battery working on charging condition,when the DG system running at near zero power input and zero power factor condition, the essence of which is to grid pure capacitive load compensation.

As the power grid load is mainly inductive load,they need to absorbed reactive power from power grid when load running,making the power factor decreased, reducing active power line transmission capacity, and reduce the overall system utilization and efficiency of electricity. If add the capacitive load in the transmission lines, can improve the power factor.Therefore, if control the input power and power factor is close to zero ,when the energy storage battery working on charging model will significantly increase the total power factor of power network.This is called the synchronous condenser control mode.

\section{Under the different control modes power relationship analysis between DC micro-grid and public AC network}

If $\dot{\mathrm{U}}=\mathrm{U} \angle 0^{\circ}, \dot{\mathrm{E}}=\mathrm{U} \angle \theta, \dot{\mathrm{I}}=\mathrm{I} \angle \phi$ In the storage battery charging and discharging process control phase angle $\theta$ and power factor angle $\varphi$, the correlation curve as shown in figure.

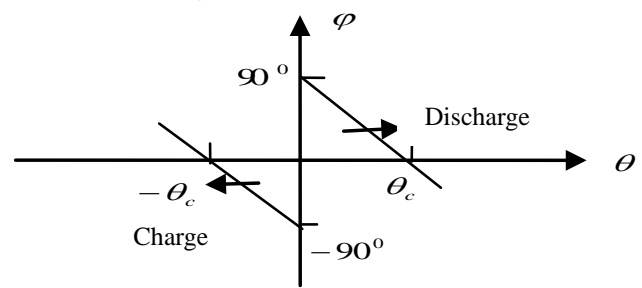

Fig.4. Adjust the relationship between power angle and power factor angle

If regard grid voltage space vector as orientation to establish d-q retangular coordinate system, as shown in figure 5.

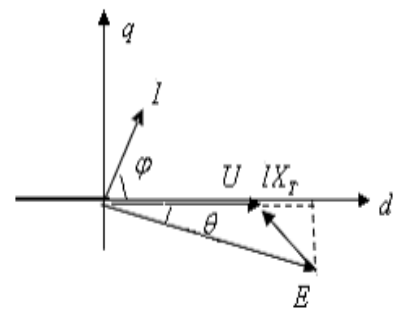

5 (a) Storage battery charge

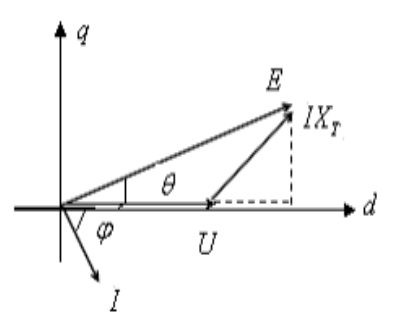

5(b) Storage battery discharge

Fig.5 D-q coordinates vector diagram

Apparently have relations: charge: $\quad \dot{U}=\dot{E}+j\left(\dot{I}_{d}+\dot{I}_{q}\right) \cdot X_{T}$

Discharge: $\dot{E}=\dot{U}+j\left(\dot{I}_{d}+\dot{I}_{q}\right) \cdot X_{T}$

$P=I_{d} U$

$Q=I_{q} U$

Charging condition, By formula (3) have, 


$$
\begin{aligned}
& U=E \cdot e^{j-|\theta|}+\left(I_{d} \cdot e^{j 9^{0}} f I_{q} \cdot e^{j 1}{ }^{0}\right)^{\beta} X_{T}^{0} \\
& U=E \cos |\theta|-I_{q} X_{T} \\
& 0=-j E \sin \theta \mid+j I_{d} X_{T} \\
& I_{q}=\frac{U-E \cos \$ \theta \mid}{X_{T}} \\
& I_{d}=\frac{E \sin |\theta|}{X_{T}}
\end{aligned}
$$

By equation (5), (6) to give the active and reactive power, respectively (9), (10)

$$
\begin{aligned}
& P=\frac{U \cdot E}{X_{T}} \sin |\theta| \\
& Q=\frac{U(U-E \operatorname{co}|\theta|)}{X_{T}}
\end{aligned}
$$

By the formula (10), charging mode of distributed power generation system provide reactive power support to grid is conditional,

$$
U-E \mathrm{c} \mathrm{o} \theta \mathrm{s}<0
$$

Similarly, the discharge conditions, from formula(4) we obtain

$$
\begin{aligned}
& I_{d}=-\frac{E \sin |\theta|}{X_{T}} \\
& I_{q}=-\frac{U-E \operatorname{co} \theta \theta \mid}{X_{T}} \\
& P=-\frac{U E \sin |\theta|}{X_{T}} \\
& Q=-\frac{U(U-E \operatorname{co} 0|\theta|)}{X_{T}}
\end{aligned}
$$

By the formula (10), discharging mode of distributed power generation system provide reactive power support to grid is conditional

$$
U-E \text { c } \mathrm{d} \theta \mathrm{s}>0
$$

When the power factor angle $\varphi=0^{0}$, the power angle $\theta_{\text {c }}$ and the power transmission system parameters have the following relationship:

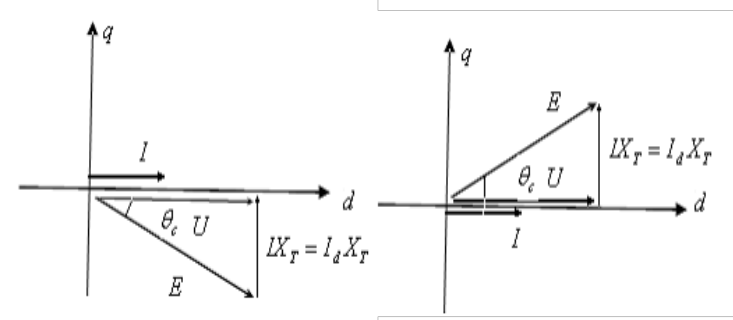

6(a) Storage battery charge 6(b)Storage battery discharge Fig.6. D-q coordinates vector diagram when power factor angle $\varphi=0^{\theta}$ charge: $\dot{\mathrm{U}}=\dot{E}+\dot{\mathrm{j}}_{\mathrm{d}} \mathrm{X}_{\mathrm{T}}$

discharge: $\dot{\mathrm{E}}=\dot{\mathrm{U}}+\dot{\mathrm{j}}_{\mathrm{d}} \mathrm{X}_{\mathrm{T}}$ 


$$
\begin{aligned}
& I_{d}= \pm \frac{E \sin \left|\theta_{c}\right|}{X_{T}} \\
& I_{q}=0 \\
& P= \pm \frac{U \cdot E \sin \left|\theta_{c}\right|}{X_{T}} \\
& Q=0
\end{aligned}
$$

Charging case equation (19), (21) take "+", discharge conditions take "-".

\section{Conclusion}

The intelligent three-port power conversion module that support photo-voltaic power generation into grid ,adopting double PWM networking mode,regarding the users transmission line as AC micro-grid. Grid-connected operation, as a result of utility grid voltage support and active energy supplement, so can greatly reduce the configuration of the DC micro-grid energy storage battery. Island running, due to the AC micro-grid isolated from the utility grid, so the isolated network operation has strong low penetration ability, improve the reliability of micro-grid users' power supply, the island fault detection and communication and fault protection,etc technical requirements are greatly reduced.

\section{References}

[1] Li Peng, Zhang Ling, Sheng Yinbo. The effective way of New energy and renewable energy grid generation large-scale application micro-grid technology[J].Journal of North China Electric Power University, 2009, 36 (1):10-14

[2] Ding lei, Pan Zhencun, Wangbin Analysis of influence of dispersing power grid on power supply reliability Wang Bin.Automation of Electric Power Systems, 2007, 31( 20) : 89-93.

[3] Benjamin K, Robert L, Toshifumi I, et al. A look at microgridtechnologies and testing, projects from around the world[J]. IEEE Power and Energy Magazine,2008,6(3):41-53.

[4] Rahimi F, Ipakchi A. Overview of demand response under the smart grid and market paradigms[C]//2010 Innovative Smart Grid Technologies (ISGT). Gaithersburg,MD,USA:IEEE, 2010: 1-7.

[5] Huang Bibin .Model Analysis and Transient Simulation of DC Distributed and Storage System.[Doctoral Degree Thesis],Tianjin,Tianjin University,2011

[6]Tang Yunqiu、Shi Nai, Electrical Motor, China Machine Press 2005 